Universidade de Brasília

Centro de Excelência em Turismo

Turismo de Negocio e Lazer

Márcia Isdebski Salles

Mariana Isdebski Salles

Monografia apresentada ao Centro de Excelência em Turismo da Universidade de Brasília como requisito parcial para a obtenção do certificado de Especialista em Gestão da Hospitalidade.

Brasília, DF, Novembro de 2003. 
UNIVERSIDADE DE BRASÍLIA

Centro de Excelência em Turismo

Turismo de Negocio e Lazer

Curso de Especialização em Gestão da Hospitalidade

\title{
Turismo de Negócio e Lazer \\ Estudo Comparativo sobre seu Desenvolvimento
}

\author{
Márcia Isdebski Salles
}

Banca Examinadora

Mariana Isdebski Salles, Mestre em Música

Orientador

Membro da Banca

Brasília, DF, Novembro de 2003. 
SALLES, Márcia Isdebski

Turismo de Negócio e Lazer: Estudo Comparativo sobre seu desenvolvimento / Marcia Isdebski Salles. Brasília, UnB/CET, 2003. $22 f$.

Monografia Gestão da Hospitalidade - Universidade de Brasília, Centro de Excelência em Turismo, Brasílai, 2003.

Área de Concentração: Turismo

Orientadora: Mariana Isdebski Salles

1. Hospitalidade. 2. Turismo. 3. Turismo de Negócio - Monografia. 
Márcia Isdebski Salles

\title{
Turismo de Negócio e Lazer \\ Estudo comparativo sobre seu desenvolvimento
}

\author{
Comissão Avaliadora
}

Mariana Isdebski Salles, Mestre em Música

Orientador

Membro da Banca

Membro da Banca

Brasília, DF, Novembro de 2003. 
À meus Pais e Irmãos

Vicente Salles Marena Salles Mariana Salles e Marcelo Salles 
Agradeço a milha família por todo incentivo e apoio, em especial a minha irmã Mariana Salles, mestra e professora da UniRio por me orientar e aceitar o desafio, como de hábito, de engajar-se na elaboração e execução de mais um projeto, chegando a este resultado; a meu pai, professor e historiador Vicente Salles, Doutor Honoris Causa pela Universidade da Amazônia, Belém, por coadjuvar com minha irmã, fornecendo importantes detalhamentos históricos para o desenvolvimento do que aqui foi apresentado; a minha mãe professora Marena Salles pela última revisão; a meu irmão Marcelo Salles e a Dra. Ângela Sampaio pelo força e incentivo, nos momentos de desânimo. Obrigado a todos pelo suporte, pela paciência sem os quais não seria possível realizar este trabalho. 
O difícil não é impossivele o fácil não tem valor.

(Provérbio Chinês) 


\section{RESUMO}

Turismo de Negócio e Lazer - Estudo comparativo sobre seu desenvolvimento, aborda a busca pelo entendimento dos motivos que levaram a um crescimento diferenciado destes dois segmentos importantes para a Hospitalidade. De forma distinta, ambos possuem um forte impacto sobre o setor. Todavia, numa simples visita à biblioteca contatasse de imediato a diferença no volume de obras para ambos os setores. Esta dificuldade em obter dados específicos sobre o Turismo de Negócio se reflete neste trabalho, mas nem por isso deixa-se de obter informações interessantes sobre o problema estudado. Historia, demanda e conceituações formam as bases de desenvolvimento deste estudo o qual acreditamos ser apenas o começo de uma interessante abordagem e debate, em especial, sobre o Turismo de Negócios. 


\section{SUMÁRIO}

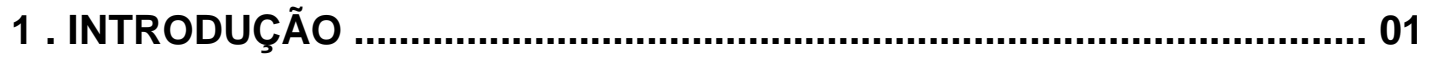

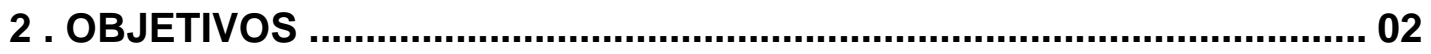

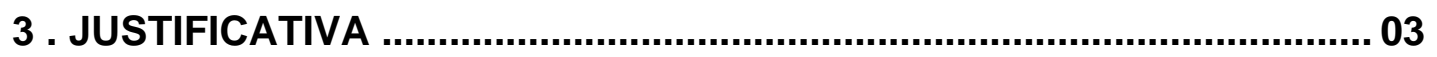

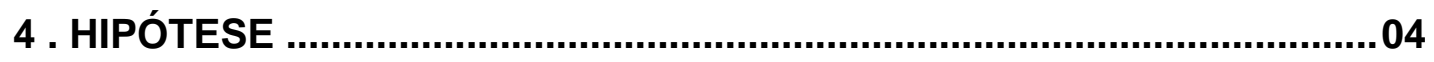

5. PROCEDIMENTOS METODOLÓGICOS ................................................ 05

6. REFERENCIAL TEÓRICO ................................................................. 06

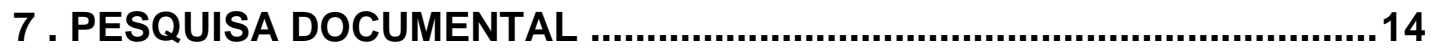

8 . CONCLUSÃO ....................................................................................... 16

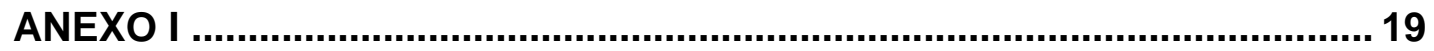

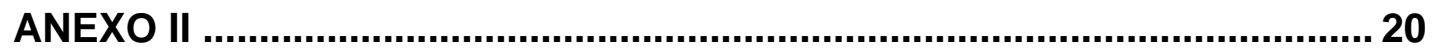

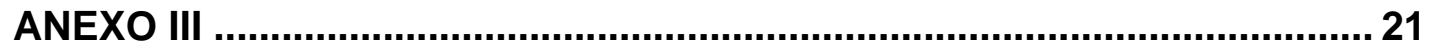

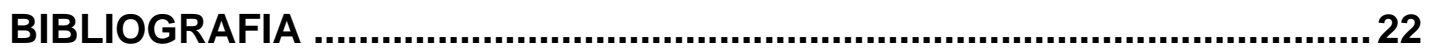



1 . INTRODUÇÃO

O presente trabalho constitui requisito indispensável à conclusão do curso de Especialização Gestão da Hospitalidade do Centro de Excelência em Turismo - CET da Universidade de Brasília - UnB.

Abordaremos dentro da temática da Hospitalidade um estudo sobre a questão que levou a centralização do desenvolvimento do Turismo exclusivamente sobre o Lazer conduzindo o ramo de Negócio para posição secundária. O que levou a ciência da Hospitalidade a este foco, uma vez que historicamente a realização de negócios foi uma das atividades propulsora do turismo.

Como metodologia utilizaremos a técnica de abordagem dialética, baseada nos procedimentos metodológicos, históricos e comparativos, realizando a coleta de dados através da documentação indireta mediante pesquisa bibliográfica e documental. 


\section{OBJETIVOS}

O presente estudo tem como objetivo geral identificar os fatores que levaram ao maior desenvolvimento do Turismo de Lazer como Ciência em relação ao Turismo de Negócio. Para alcançá-lo consideramos necessário vencer os seguintes objetivos específicos:

a) Verificar a real ocorrência de tratamento científico diferenciado dado ao Turismo de Lazer e ao Turismo de Negócios;

b) Identificar os fatores históricos que ocasionaram esta diferença de tratamento entre estes dois tipos de Turismo; e

c) Verificar o impacto que o tratamento científico diferenciado entre Turismo de Lazer e de Negócio individualmente causam sobre a indústria da Hospitalidade. 


\section{JUSTIFICATIVA}

É fato conhecido que as empresas são criadas para dar lucro, para garantir o sustento, a sobrevivência de seu empreendedor, de sua família, de seus funcionários e principalmente o da própria empresa. Hoje, economicamente, o mercado considera viável apenas aqueles empreendimentos que tenham projeção de rendimento no mínimo superior ao da poupança. O mercado busca o maior lucro, a constante superação de suas metas e dentro desta constante disputa as empresas, assim como as pessoas, procuram inserir-se nas áreas que se destacam na geração de maior retorno financeiro com menor custo, esforço e riscos. Diante desta visão de mercado é no mínimo curioso questionar por que no ramo da Hospitalidade esta regra básica do mercado financeiro aparentemente torna-se secundária. Ou seja, por que o ramo de Turismo de Negócios, que gera maior arrecadação que o Turismo de Lazer, teve menor desenvolvimento e interesse científico? ${ }^{1}$

Para a ciência da Hospitalidade acreditamos que este trabalho levanta interessante questionamento sobre o foco no qual a mesma se desenvolve, gerando reflexão sobre as escolhas humanas que culminaram na atual condição, de maior produção literária e científica sobre o turismo de lazer, em que se encontra a Ciência da Hospitalidade.

Para as empresas do setor estas reflexões podem representar incentivos para repensar o seu nicho de trabalho e a maneira com que vem tratando sua atividade econômica e, ao mesmo tempo, repensar a Ciência da Hospitalidade.

Pessoalmente, o desenvolvimento deste trabalho, além de suprir uma curiosidade criada durante o curso, representa nova oportunidade de desenvolver e aprimorar conhecimentos técnicos, de análise, síntese, comunicação e, conseqüentemente, possibilitar maior aproximação da autora nesta área de seu interesse.

\footnotetext{
${ }^{1}$ Anexo II
} 


\section{HIPÓTESES}

As hipóteses que se pretende verificar através do desenvolvimento deste trabalho são:

a) Durante anos o Turismo teve sua conceituação básica restrita única e exclusivamente à atividade de lazer, impossibilitando-o de abranger outras modalidades de Turismo;

b) A maior ocorrência do estudo de Turismo focado ao Lazer deve-se a ligação direta do tema a atividades que proporcionam prazer aos relatores ${ }^{2}$, muitas vezes desenvolvidas em seu tempo livre durante o qual perceberam a carência de atendimento profissional na mesma; e

c) O Turismo de Negócio gera maior arrecadação, pois decorre da necessidade de empresas e pessoas se deslocarem para fechar negócios, obrigando-as a aceitar o que o mercado oferece e cobra para proporcionar a efetivação destes negócios.

\footnotetext{
${ }^{2}$ Os primeiros relatos de viagens baseiam-se em especial sobre descrição de viajantes com intenção de descrever o que viam, sem necessariamente um intuito científico.
} 


\section{PROCEDIMENTOS METODOLÓGICOS}

Neste estudo sobre a diferenciação do tratamento dado ao desenvolvimento do Turismo de Lazer e de Negócio, conforme proposto por Maria Margarida de Andrade, utilizamos para realização da pesquisa o método de abordagem dialético pelo qual buscamos investigar a realidade pelo estudo de sua ação recíproca. ${ }^{3}$

Em relação às etapas utilizamos, como procedimento, o método histórico, a fim de entendermos o que gerou e incentivou a diferenciação de tratamento entre Turismo de Negocio e Turismo Lazer para chegarmos, finalmente, à posição atual da Hospitalidade; e o método comparativo verificando justamente as semelhanças e explicando as diferenças ${ }^{4}$ que ocorreram durante este processo.

Quanto à coleta de dados, esta foi efetuada mediante documentação indireta, ou seja, por meio de pesquisa bibliográfica e documental.

\footnotetext{
${ }^{3}$ Andrade: 2001; 132.

${ }^{4}$ Andrade: 2001; 134.
} 


\section{REFERENCIAL TEÓRICO}

A hospitalidade é uma atividade que acompanha o homem desde o início de sua locomoção por diferentes sociedades ${ }^{5}$. Todavia, seu desenvolvimento como ciência foi tardio. Para Marutschka Moesch isto se deve ao fato de:

"O turismo nasceu e se desenvolveu com o capitalismo. A cada avanço capitalista, há um avanço do turismo. A partir de 1960, o turismo explodiu como atividade de lazer, envolvendo milhões de pessoas e transformando-se em fenômeno econômico, com lugar garantido no mundo financeiro internacional. Desde 1995, o fluxo turístico cresce a uma taxa anual média de 4,3\%, enquanto a expansão máxima da riqueza mundial tem sido de 3\%, aproximadamente. Em 1997, o setor empregava 250 milhões de pessoas, uma entre cada dez pessoas da população mundial economicamente ativa, conforme a Organização Mundial do Turismo - OMT (1998)."

(2002:9)

A hospitalidade a que nos referimos aqui está relacionada ao conceito mais amplo e moderno de tratamento desta ciência, envolvendo hospedagem, alimentos e bebidas, entretenimento e deslocamento. ${ }^{6}$ o objetivo da utilização desta denominação mais ampla sobre todas as atividades que envolvem o turismo visa: "troca-se um recorte mais ou menos preciso por um recorte impreciso e ambíguo (...) enriquecendo a perspectiva de ensino e pesquisa no setor". ${ }^{7}$ Acredita-se que por se tratar de uma discussão contemporânea muito do que se tem escrito até então esteja relacionado ao termo turismo e não à Hospitalidade. Esta é discussão que o autor Luiz Octávio L. Camargo levanta concluindo que:

"Espera-se que as ciências aplicadas ao turismo (...) -, ao lazer e à comunicação percebam a riqueza de um recorte do conhecimento científico moldado sobre o fenômeno ou sobre o fato social associado ao gesto humano de receber."

$(2003 ; 20)$

\footnotetext{
${ }^{5}$ Aqui adotamos como conceito de sociedade o agrupamento de seres humanos que vivem em estado gregário (Aurélio: 1986; 1602).

${ }^{6}$ Conceito adotado no primeiro módulo deste curso - Análise da Indústria da Hospitalidade - junto à professora Mariana Aldrigui Carvalho.

${ }^{7}$ CARVALHO, Texto de Luiz Octavio L Camargo: 2003; 20.
} 
Cientificamente essa nova área do conhecimento humano está baseada em diferentes disciplinas. Conforme Jordi Montaner Montejano relata em seu trabalho:

"O fenômeno turístico é uma atividade humana baseada em uma série de disciplinas relacionadas com as ciências sociais e humanas. (...)"

(2001; 01)

"O turismo, devido a esses vínculos, converte-se em uma disciplina técnico-científica que está estreitamente relacionada com outras disciplinas e conhecimentos científicos, dando-Ihes um vínculo interdisciplinar e multidisciplinar."

(2001; 07)

Esclarecida a relação do tratamento do turismo dentro da Ciência da Hospitalidade, compreende-se o posicionamento do estudo aqui proposto dentro da abordagem do curso.

Pesquisando-se a denominação de Turismo, encontramos no Dicionário Aurélio o conceito básico do vocabulário comum em nosso país, descrito como sendo:

1. Viagem ou excursão feita por prazer, a locais que despertam interesse. 2. 0 conjunto dos serviços necessários para atrair aqueles que fazem turismo (1) e dispensar-Ihes atendimento por meio de provisão de itinerário, guias, acomodações, transporte, etc. 3. O movimento de turistas: (...)

Prazer, por sua vez é definido como: agradar, distração, divertimento, diversão (1986). Percebe-se que o foco da conceituação do Turismo nesta definição, encontrada em uma das mais recentes edições de nosso dicionário, está voltado exclusivamente ao Lazer (que por sua vez é denominado como: ócio, descanso, folga (...) Tempo que se pode dispor depois dos afazeres (para) divertimento, entretenimento, distração, a recreio (1986)). Nesta mesma linha, encontramos o conceito de Turista que vai um pouco além, na medida que possibilita leve percepção de tratamento diferenciado entre as pessoas que se deslocam: pessoa que faz turismo. (...) 3. Diz-se de classe ou passagem de preço mais econômico para os viajantes (1986). Percebe-se aqui uma diversificação na 
prestação de serviço de transporte, em termos financeiros, indo um pouco mais além, verificamos que os viajantes a que se refere esta definição são pessoas que viajam por lazer. Verificamos neste levantamento não haver referência a nenhuma outra modalidade de Turismo, em especial ao Turismo de Negócio.

Segundo a conceituação etimológica da palavra turismo verifica-se que ela deriva do francês tour (Cunha:1982; 798), que, por sua vez, significa volta, dar uma volta, dar uma volta a algo (Larousse: 1998; 239). A expressão idiomática "dar uma volta" retrata a necessidade de espairecer, relaxar, passear; ou seja, realizar uma atividade que nada tem a ver com a atividade rotineira de uma pessoa, com a atividade de sustento dessa pessoa. Com esta origem, fica fácil compreender o por que do turismo restringir ao lazer sua abrangência dentro do universo dos motivos das viagens.

Para a Hospitalidade, definir, sobretudo universalmente, uma linguagem que padroniza os principais termos do turismo esbarra na constante adaptação desta Ciência viva às necessidades do novo tempo como também no desenvolvimento não homogeneizado desta atividade econômica pelo mundo. Leonard Lickorish e Carson Jenkins retratam bem esta situação:

“(...) não existir uma estrutura comum que represente esta indústria em todos os países. (...) Mesmo os principais componentes da indústria do turismo, como acomodações e transporte, variam de um país para outro."

(2000; 09)

Mesmo diante destas dificuldades, Walter Hunziker e Kurt Krapf formulam em 1942 a definição de que:

O turismo é a soma de fenômenos e relacionamentos quer surgem das viagens e de estadas de indivíduos não-residentes, na medida em que não visam a uma residência permanente e não são ligados a atividades remuneradas.

(Lickorish e Jenkins: 2000; 50)

Em 1968, as Nações Unidas aprovaram como diretriz para o setor a seguinte denominação: 
o termo 'visitante' descreve qualquer pessoas que esteja visitando um país que não seja o seu local de residência, por qualquer motivo que não seja uma ocupação remunerada no país visitado.

(Lickorish e Jenkins: 2000; 51)

Em 1981 Burkart e Medlik adaptam o conceito de Hunziker e Krapf, sobre Turismo para:

O fenômeno que surge de visitas temporárias (ou estadas fora de casa) fora do local de residência habitual por qualquer motivo que não seja uma ocupação remunerada 'grifo meu' ${ }^{8}$ no local visitado.

(Lickorish e Jenkins: 2000; 10)

Percebe-se que em todas estas definições de Turismo há referência a não remuneração no local visitado, ou seja, a não gratificação por serviços prestados, mediante salário, honorários, renda (Aurélio: 1986; 1484). Verificamos assim a total desvinculação do Turismo de Negócio ao universo daquele conceito de Turismo proposto pouco mais de meio século atrás. Se a origem do turismo está vinculada à necessidade inicial do homem expandir seu negócio, sua área de comercialização - "a invenção do dinheiro pelos sumérios (babilônios) e o desenvolvimento do comércio, em torno de 4000 a.C, marca o início da era moderna das viagens" (Goeldner: 2002; 43) -, como se deu este distanciamento do Negócio dentro do Turismo?

Lickorisch e Jenkins relatam que a mudança da viagem por motivos sérios (para fins comerciais, profissionais ou de saúde e educação) "para viagens por prazer ocorreu gradualmente" (2000; 33), devendo-se o fato à natureza da demanda $(2000 ; 11)$.

Edmund Swinglehurst ${ }^{9}$, relata que as viagens que iniciaram com as primeiras migrações humanas da África para o mundo. No Oriente Médio e Egito, avançando um pouco na História, nos deparamos com viagens empreendidas a mercados para a venda de produtos, fuga da fome, inundação ou guerras. Relato

\footnotetext{
${ }^{8}$ Consideramos como atividade não remunerada aquela não responsável pela sobrevivência do indivíduo ou da empresa.

${ }^{9}$ Theobald cap 6 p 103.
} 
que fortalece a idéia do turismo ser proveniente do negócio. Este processo sofre sua primeira grande retenção com a queda do império romano só voltando a se reestruturas durante a Guerra Santa quando se restabeleceu a lei e a ordem. $O$ autor observa ainda que neste período havia grande miscigenação social entre os povos devido à desvinculação com o conceito de nação.

Para Lickorisch e Jenkins (2000), o turismo começou a apresentar movimento significativo somente após o século XVII, apontado como fato gerador das primeiras discussões sobre turismo os "grand tour" (viagens educacionais) empreendidos por jovens aristocratas, que, em seu retorno, argumentavam contra e a favor do valor desta cansativa e longa jornada incentivada por representar a possibilidade de enriquecimento de conhecimento para seu próprio país. Todavia a realização de viagens continuava restrita a expedições exploratórias, à guerra, a migrações religiosas, aos estudos e a elite, esta com objetivo de tratamento de saúde.

Goeldner alerta que: "embora fazer o grand Tour tenha-se tornado uma experiência educacional, ela foi criticada como tendo se degenerado em uma simples busca do prazer" (2002; 49).

Swinglehurst (2002) reforça esta idéia ao expor que no séc. XVIII o Grand Tour tinha como objetivo criar base cultural para as famílias da nova classe de ricos provenientes das viagens comerciais marítimas inglesas. Declara as mesmas como infrutíferas uma vez que os jovens não conheciam outra língua, mantinham contato com a população nativa do tipo amo-criado, reclusos a vila de amigos em palacetes cercados por casebres da população pobre, com raras visitas a igrejas e museus.

Continuando com a descrição de Lickorisch e Jenkins (2000) sobre a gradação desta modificação de foco, nos deparamos com o deslocamento do centro de produção da agricultura para a indústria, mais especificamente quando esta superara a geração da mais valia daquela, mudando o centro da economia mundial, possibilitando a melhoria nos meios de transporte ${ }^{10}$, conseqüentemente,

${ }^{10}$ Aumento na velocidade e na capacidade de transportar maior número de pessoas de uma única vez. 
temos uma mudança social quando a melhor distribuição de renda e irradiação das férias remuneradas ${ }^{11}$. Estes fatores juntos geraram as condições ideais para que o Turismo deixasse de ser uma exclusividade da elite européia, expandindose pela sociedade.

Swinglehurst (2002: 107) relata que neste contexto surge Thomas Cook com suas as primeiras excursões, criando condições seguras para expandir as viagens além da Inglaterra, todavia a continuação de uma postura arrogante dos ingleses continuou impedindo-os de absorver a cultura local, eles incutiam suas idéias nas localidades visitadas por estas dependerem financeiramente deste contato (Theobald: 2002:106). Apesar de ser a sociedade que mais viajava no mundo, em 1960 "nem 2\% dos ingleses viajavam de férias para o exterior." (Theobald: 2002: 110), quando o Turismo de Massa começou a dar seus primeiros passos, as restrições impostas pela Segunda Guerra sobre restrição de gastos em outros países, acaba sendo elemento equilibrador do turismo, misturando classes e possibilitando uma miscigenação social principalmente pelos jovens.

Após a Segunda Grande Guerra é que notamos os maiores avanços, impulsionados pelo crescimento do turismo de massa e em especial pela própria exigência de segmentação do mercado, imposto pelos consumidores. É quando o setor de Turismo de Negócio volta a se expandir utilizando novas formas como: viagens organizadas para convenções, conferências e feiras, trade shows, viagens de incentivo. Todavia somente em 1994 o Turismo de Negócios aparece oficialmente como segmento do Turismo, quando a World Turism Organization WTO aprovou acordo que revia as definições do setor no qual:

O turismo compreende "as atividades de pessoas que viajam e permanecem em locais fora de seu ambiente usual, por não mais de um ano consecutivo, para fins de lazer, negócios 'grifo meu' e outros." (...) O "turismo" se refere a todas as atividades de visitantes incluindo "turistas" (visitantes que passam a noite no local) e "visitantes de um dia".

(Lickorish e Jenkins: 2000; 53)

\footnotetext{
${ }^{11}$ Tanto no aspecto de aumento do número de dias de férias remunerado como no aumento do número de pessoas conquistando este direito.
} 
Hoje a definição adotada pela Organização Mundial do Turismo - OMT para o turismo consiste em:

O conjunto de atividades realizadas pelas pessoas durante suas viagens e estadas em lugares distintos de seu ambiente habitual, por um período de tempo consecutivo inferior a um ano, com finalidade de lazer, negócio 'grifo meu' e outros motivos, e não por razões lucrativas.

(Montejano: 2001; 02)

Percebemos que durante o desenvolvimento do Turismo ocorreu, sobretudo na última década, a ampliação de sua abrangência, a definição deixa de ser exclusivamente limitada ao lazer. Também percebes-e que durante todo o período ocorre a vinculação direta do Turismo com o ato de viajar. Definido pelo citado Aurélio como: ato de ir ver alguém por cortesia, dever ou afeição. (...) vistoria, inspeção (1986). Isso nos leva a concluir que viajar é um pressuposto para se fazer Turismo, independente do motivo. Melhor ainda, a viagem é que possibilita unir diferentes motivos dentro de uma mesma categoria, enriquecendoa para seu melhor e mais profundo estudo.

Partindo para uma visão econômica da Hospitalidade nos deparamos com a atividade que se tem apresentado como um dos crescimentos mais significativos no mundo atual:

"O turismo constitui uma das mais notáveis historias de sucesso dos tempos modernos. Seu crescimento em escala maciça começou somente na década de 1960, e registrou uma evolução rápida e constante nos últimos trinta anos em termos de faturamento gerado e do número de pessoas que viajam ao exterior. O setor tem mostrado uma grande capacidade de adaptação nas épocas de crises econômicas, e, no próximo século, continuará crescendo a uma considerável taxa anual de quase $4 \% . "$

(Theobald: 2002; 15)

Paralelo a isto, a Hospitalidade tem uma característica de não essencialidade à sobrevivência humana que lhe causa total vulnerabilidade às crises econômicas, sobretudo para o Turismo de Lazer. Numa crise qualquer, deixar de realizar atividades de lazer, abdicar do Turismo de Lazer, é uma opção. 
Todavia esta possibilidade não é verdadeira para as empresas, para as quais as viagens de negócio representam uma necessidade e não um luxo.

Nos períodos de declínio ou recessão nos negócios, as empresas podem optar por uma tarifa aérea em uma classe mais barata, por hotéis mais baratos em vez dos mais caros, ou mesmo limitar a duração e o número de viagens. Abrir mão de férias anuais não será uma ameaça ao turista em potencial; não conseguir superar condições de recessão pode ser uma grande ameaça para um negócio. Então, viagens de negócio, mesmo em níveis mais inferiores, irão continuar, ao passo que as viagens a lazer podem sofrer uma grave queda devido a circunstâncias econômicas predominantes.

(Lickorish e Jenkins 2000; 77)

Neste contexto, percebemos que o segmento de Turismo de Negócios possui papel relevante na Hospitalidade pela sua constante demanda em virtude de manter a sobrevivência das empresas, dando continuidade em seu trabalho e conseqüente expansão. Luiz Rufino F. Filho nos fornece clara explicação sobre o por quê da inclusão do Turismo de Negocio na Hospitalidade:

A ONU classifica as viagens de negócio como turísticas não por causa da natureza das viagens, mas por considerar prioritária a demanda significativa e constante dos empresários e executivos ao mercado de bens e serviços turísticos.

As pessoas que viajam por motivos profissionais utilizam os equipamentos e serviços e, em seu tempo livre, usufruem das atrações como qualquer turista convencional. 


\section{PESQUISA DOCUMENTAL}

Retornando a questão da demanda, através do levantamento estatístico da Embratur - Instituto Brasileiro de Turismo ${ }^{12}$, entre 1997 e 2001, observamos que na atualidade a demanda pelo Turismo de Lazer $^{13}$ tem se mostrado maior que o dobro da demanda pelo Turismo de Negócio. Á uma diferenciação na ordem de $49,1 \%$ em 1998, chegando a $79,6 \%$ em 1999 e caindo para $55,5 \%$ em 2001. A queda nesta diferenciação deve-se ao acréscimo de novas categorias ao estudo visando atender a recomendação da OMT, de 1999. É importante ressaltar que a redistribuição dos índices afetou exclusivamente o Turismo de Lazer, mantendo-se estável o índice do Turismo de Negócio. Cabe ainda observar que se anexarmos os indicadores dos motivos de congressos e convenções ao universo do Turismo de Negócio, que vem girando na ordem de 4\%, conforme sugerido por Lickorish e Jenkis $^{14}$, haveria mudança nesta realidade, pouco significativa se considerarmos os padrões até 1999 e representativa para os anos consecutivos. Todavia se a ordem é segmentar para melhor entender e atender o Turismo esta sugestão estaria na contramão da tendência da Hospitalidade. Mesmo com esta diferenciação na abordagem desses índices o que podemos afirmar é que o Turismo de Lazer continua tendo demanda significativamente maior que o Turismo de Negócio sendo este um dos fatores que justificam o maior empenho da Hospitalidade sobre o Turismo de Lazer.

Outro fator importante que devemos analisar é o gasto per capita que os turistas destes dois segmentos despendem. A EMBRATUR ${ }^{15}$ aponta que um Turista de Negócio gasta ao dia US\$ 137,56 (cento e trinta e sete dólares e cinqüenta e seis cents) contra US\$77,09 (setenta e sete dólares e nove cents) gastos pelos Turistas de Lazer. Aqui verificamos uma reversão quanto ao

\footnotetext{
${ }^{12}$ Anexo I

${ }^{13}$ Consideramos que o "motivo turismo" trata-se do lazer em si, uma vez que este não é listado conforme os demais motivos listados. O estudo utilizado não apresenta nota explicativa sobre a questão.

${ }^{14}$ Situação citada no

${ }^{15}$ Anexo II parágrafo, da pagina desta.
} 
apontado na demanda. O gasto de recursos de um turista de negócios representa o dobro que o turista de Lazer despende. Este fato é forte argumento da importância do Turismo de Negocio no mercado.

Analisando os dois fatores, demanda versus gasto diário, juntos, notamos que mesmo tendo uma capitação menor dos gastos dos turistas, 0 Turismo de Lazer acaba por se sobressair em relação ao Turismo de Negócios em virtude de sua superior demanda. Comparando-se diretamente a arrecadação gerada pela total populacional representativo deste estudo ${ }^{16}$ contatamos a ocorrência de variação na ordem de $12,27 \%$ entre os dois segmentos. Fato que vem a fortalecer novamente o Turismo de Lazer.

${ }^{16}$ Anexo III 


\section{CONCLUSÃO}

O Turismo de Lazer possui maior desenvolvimento que o Turismo de Negócios. Tal ocorrência deve-se à conceituação restrita (conforme a origem etimológica da palavra) e a superior demanda do mercado.

De acordo com o Referencial Teórico levantado verificamos que o primeiro fator a motivar a restrição ao lazer está na própria raiz da palavra Turismo, em sua própria definição. O conceito ainda preso e restrito a um único motivo de viagem incentivou o tratamento cientifico focado no Turismo de Lazer, em razão da própria definição adotada, que só foi revista na última década do século $\mathrm{XX}$, por necessidade do mercado, quando os consumidores começaram a exigir tratamento especializado para atender as necessidades especificas dos diferentes motivos de viagem.

A própria luta do Turismo para se impor como Ciência Aplicada exigiu de si uma formação multidisciplinar que necessita simultaneamente de embasamento em outras ciências e subdivisões para melhor ser entendida.

Mas não é apenas em detrimento da origem etimológica da palavra Turismo que se restringiu seu estudo. Historicamente, pela bibliografia encontrada, parece-nos que a conscientização da representatividade e importância social e econômica de viajar demorou a tornar-se relevante. E quando a mesma desponta a demanda significativamente superior pelo lazer, pela busca de afastamento do habitual, acaba por ofuscar outros motivos de viagem. Os livros utilizados como referencial que tratam da Historia do Turismo se baseiam quase que exclusivamente ao Turismo de Lazer. Acreditamos que a exploração de textos antigos, com a visão que hoje possuímos da Hospitalidade, poderia ser formulado melhor entendimento do Turismo por motivo de Negocio, Religião, Guerra, pois, apesar de em menor volume, as mesmas não deixaram de ocorrer, e mesmo assim desaparecem na descrição dos autores. Porém este estudo exigiria maior 
profundidade de análise, superior tempo de pesquisa em relação à proposta de trabalho do curso.

Voltando à demanda, os dados colhidos junto a Embratur apontam significativa diferença a favor do Turismo de Lazer em relação ao Turismo de Negócio em termos de volume o que acaba por viabilizar mais este setor. Mas o nicho de Turismo de Negócios possui dois fatores fortes: continuidade de ocorrência mesmo em épocas de crises econômicas e significativo gasto dos viajantes. Características essas que acabam por gerar esforço diferenciado para atração deste público, a menos que se pretenda tornar comercial uma área que não possui esta tradição, a exemplo da implementação das chamadas "zonas francas" de negócios ou de indústrias. Acreditamos que o Turismo de Negócios tem um trabalho de marketing mais focado, depende principalmente da manutenção, da fidelização de seus clientes, principal divulgador, e não da constante conquista de novos clientes, como ocorre no Turismo de Lazer que possuem tantas opções para se divertirem que nunca é certo o retorno dele ao mesmo destino. Mas isso cabe ao desenvolvimento de um trabalho especifico.

Pelo exposto, comprovamos que a primeira hipótese apontada, de que durante anos o Turismo teve sua conceituação básica restrita única $e$ exclusivamente à atividade de lazer, impossibilitando-o de abranger outras modalidades de Turismo, se confirma. Quanto à segunda hipótese levantada de que a maior ocorrência do estudo de Turismo focado ao Lazer deve-se a ligação direta do tema a atividades que proporcionam prazer aos pesquisadores, muitas vezes desenvolvidos em seu tempo livres durante o qual perceberam a carência de atendimento profissional na mesma proposta não conseguimos nenhum relato bibliográfico nem documento que a comprovasse. Teria sido interessante ampliar a metodologia de trabalho para a execução de aplicação de questionários para averiguação da questão. Abordagem esta não adotada em virtude do pouco tempo para elaboração, aplicação e, sobretudo, análise consistente e significativa da questão. A terceira e última hipótese sugerida: O Turismo de Negócio gera maior arrecadação, pois decorre da necessidade de empresas e pessoas se deslocarem para fechar negócios, obrigando-as a aceitar o que o mercado oferece e cobra 
para proporcionar a efetivação destes negócios; há uma comprovação parcial. Em termos de gasto por turista ela é verdadeira, em termos de arrecadação do nicho ela é falsa em virtude da maior demanda do Turismo de Lazer proporcionar a superação de arrecadação deste setor em relação ao de Turismo de Negócio.

Com isso, atingimos os objetivos propostos, com a ressalva de que o terceiro objetivo secundário seria melhor abordado por meio de questionários.

Concluímos que o foco do desenvolvimento do Turismo como ciência sobre o Lazer é resultado da etimologia da palavra turismo e principalmente da superior demanda para as viagens de lazer durante toda a historia. Todavia, a onda de segmentação de mercado, promovida pela modernização das técnicas administrativas, apontam que o Turismo de Negócio é um forte nicho para o mercado e a Ciência da Hospitalidade, carente, todavia, de estudos específicos que lhe assegurem maior representatividade e importância para a ciência e o mercado. 


\section{ANEXO I}

\begin{tabular}{|l|c|c|c|c|c|}
\hline \multirow{2}{*}{ Motivo da Viagem } & \multicolumn{5}{|c|}{ Ano } \\
\cline { 2 - 6 } & 1997 & 1998 & 1999 & 2000 & 2001 \\
\hline Turismo & $65,3 \%$ & $71,8 \%$ & $77,6 \%$ & $57,0 \%$ & $55,5 \%$ \\
\hline Negócios & $28,3 \%$ & $22,7 \%$ & $18,0 \%$ & $23,4 \%$ & $24,3 \%$ \\
\hline Visitar familiares & - & - & - & $10,9 \%$ & $10,6 \%$ \\
\hline Congressos / Convenções & $4,3 \%$ & $4,0 \%$ & $3,2 \%$ & $4,5 \%$ & $5,9 \%$ \\
\hline Estudo / ensino / pesquisa & - & - & - & $1,5 \%$ & $1,1 \%$ \\
\hline Tratamento de Saúde & - & - & - & $1,5 \%$ & $0,1 \%$ \\
\hline Religião / Peregrinação & - & - & - & $0,2 \%$ & $0,1 \%$ \\
\hline Outros & $2,1 \%$ & $1,6 \%$ & $1,2 \%$ & $1,0 \%$ & $2,2 \%$ \\
\hline
\end{tabular}

(EMBRATUR:2001; 14)

Diferença entre o percentual de Turismo e Negocio

\begin{tabular}{|l|c|c|c|c|c|}
\hline \multirow{2}{*}{ Motivo da Viagem } & \multicolumn{5}{|c|}{ Ano } \\
\cline { 2 - 6 } & 1997 & 1998 & 1999 & 2000 & 2001 \\
\hline Turismo & $65,3 \%$ & $71,8 \%$ & $77,6 \%$ & $57,0 \%$ & $55,5 \%$ \\
\hline Negócios & $28,3 \%$ & $22,7 \%$ & $18,0 \%$ & $23,4 \%$ & $24,3 \%$ \\
\hline Diferença & $37,0 \%$ & $49,1 \%$ & $79,6 \%$ & $33,6 \%$ & $31,2 \%$ \\
\hline
\end{tabular}




\section{ANEXO II}

\begin{tabular}{|l|c|c|c|}
\hline Motivo da Viagem & $\begin{array}{c}\text { Permanência } \\
\text { Média (dias) }\end{array}$ & $\begin{array}{c}\text { Gasto Médio Diário } \\
\text { percapita (US\$) }\end{array}$ & $\begin{array}{c}\text { Renda Média } \\
\text { Anual Individual (US\$) }\end{array}$ \\
\hline Turismo & 11,63 & 77,09 & $23.541,22$ \\
\hline Negócios & 10,65 & 137,56 & $51.709,29$ \\
\hline Visitar familiares & 17,16 & 62,41 & $31.449,81$ \\
\hline Congressos & 8,11 & 122,99 & $46.403,56$ \\
\hline Média Global & 12,20 & 81,21 & $34.726,74$ \\
\hline
\end{tabular}

(EMBRATUR:2001; 14) 


\section{ANEXO III}

Comparação entre Demanda e Gastos - Anexo I e II

\begin{tabular}{|l|c|c|c|c|c|}
\hline $\begin{array}{l}\text { Motivo de } \\
\text { viagem }\end{array}$ & População* & $\begin{array}{c}\% \text { da população } \\
\text { por motivo }\end{array}$ & $\begin{array}{c}\text { Total da população } \\
\text { por motivo }\end{array}$ & $\begin{array}{c}\text { Gasto médio diário } \\
\text { por pessoa }\end{array}$ & $\begin{array}{c}\text { Total de gasto médio diário } \\
\text { de cada população }\end{array}$ \\
\hline Turismo & 5.248 & $55,5 \%$ & $2.912,64$ & US $\$ 77,09$ & US $\$ 224.535,41$ \\
\hline Negócios & 5.248 & $24,3 \%$ & $1.275,264$ & US $\$ 137,56$ & US $\$ 175.425,31$ \\
\hline \multicolumn{7}{|l}{ Total de gasto médio diário entre os dois motivos de viagem. } & US $\$ 399.960,72$ \\
\hline \multicolumn{4}{|l}{ Diferença de gasto médio diário entre os dois motivos de viagem. } & US $\$ 49.110,10$ \\
\hline
\end{tabular}

* total da população da amostra de turismo receptivo da pesquisa. (2001; 06)

US\$ $399.960,72 \rightarrow 100 \%$

US $\$ 49.110,00 \rightarrow ? \% \quad-\rightarrow \quad ?=12,27 \%$ 


\section{BIBLIOGRÁFIA}

AURELIO. Novo Dicionário da Língua Portuguesa. $2^{\circ}$ edição. $37^{\circ}$ edição. Rio de Janeiro: Editora Nova Fronteira, 1986.

ANDRADE, Maria Margarida. Introdução à Metodologia do Trabalho Cientifico: elaboração de trabalhos na graduação. 5ºd. São Paulo: Atlas, 2001.

CARVALHO, Mariana Aldrigui. Análise da Industria da Hospitalidade. Apostila do Centro de Excelência em Turismo da Universidade de Brasília, 2003.

CUNHA, Antônio Geraldo da Cunha. Dicionário Etimológico Nova Fronteira da Língua Portuguesa / Antônio Geraldo da Cunha; assistentes: Cláudio Mello Sobrinho ... Ist. al. I. Rio de Janeiro: Nova Fronteira, 1982.

EMBRATUR - Estudo da Demanda Turística Internacional 2001.

FILHO, Luiz Rufino F. Turismo $X$ Negócios. Brasília, Centro de Excelência em Turismo da Universidade de Brasília, 2000.

GOELDNER, Charles R. Turismo: princípios, práticas e filosofias / Charles R. Goeldner, J. R. Brent Ritchie, Robert W. Mclntosh; trad. Roberto Cataldo Costa. $8^{\circ}$ Ed. Porto Alegre: Bookman, 2002. 
LAROUSSE, de Poche. Dicionnaire Français - Portugais, Português - Fracês. Paris: 1998.

LICKORISH, Leonard J. Introdução ao Turismo. Leonard J. Lickorish, Carson L. Jenkis; Tradução de Fabíola de Carvalho S. Vasconcellos. Rio de Janeiro: Campus, 2000.

SIQUEIRA, Deis. Metodologia da Pesquisa. Centro de Excelência em Turismo da Universidade de Brasília, 2003.

MOESCH, Marutschka. A Produção do Saber Turístivo. $2^{\circ}$ ed. São Paulo: Contexto, 2002.

MONTEJANO, Jordi Montaner. Estrutura do Mercado Turístico. $2^{\circ}$ ed. São Paulo: Roca, 2001.

THEOBALD, William F. Turismo Global. William F. Theobald organizador; tradução Anna Maria Capovilla, Maria Cristina Guimarães Cupertino, João Ricardo Barros Penteado. $2^{\circ}$ ed. São Paulo: Editora Senac São Paulo, 2002.

VELLASCOS, Ana Maria de Morais Sarmento. Manual de Orientação para a Produção de Textos Acadêmicos. Centro de Excelência em Turismo da Universidade de Brasília, 2003. 